\title{
The Impact of Using Mathematical Models in the Growth of Regional Economic Indicators, Strengthening the Role of the State
}

\author{
Dr Miftar Ramosacaj \\ Math Faculty University of Vlore, Albania \\ Prof Dr Vjollca Hasani \\ University of Sheffield Business and Management, Economy International Faculty, \\ Thessaloniki, Greece
}

Prof Dr Alba Robert Dumi

Management Department,

Economy Faculty University of Vlore, Albania

\begin{abstract}
The purpose of this paper is the identification of the relationship between exchange rate and inflation directly and indirectly having their factors in the stability and development of the economy. The term "public policy" is not recent. It was introduced in the language of European political and administrative sciences in the 1970's as a literal translation of the term "public policy".Based on the society's viewpoint and its policy and policy relations, politics can be divided into three branches, which according to Anglo-Saxon terminology are called politics, policy and polity. The findings and analysis, conclusions and recommendations which will be part of important scientific studies in this paper that will serve to assist in the preservation of natural resources in our countries. Politics (polity) means consensus by the electoral body for political power and the inter-social cohesion of different groups and strata. Three aspects intertwine and influence each other by implementing complex socio-political dynamics. Another purpose is the direct impact analysis that has the exchange rate of micro economy development, macro economic factors such as economic growth, and the impact of GDP growth, inflation and employment levels. By politics it is meant the activities of various political parties or different groups to enable the possessing and having the political power. By policy are meant the laws or other legal acts implemented by the political power to manage public property.
\end{abstract}

Keywords: Math models, exchange rate, empirical studies, management public politics, state

\section{Introduction}

State, whichever is, it is the society functionary form. Charles Maurras

This paper is designed to analyze the role of good governance, the role of public policies that are essential to economic and social development, and how these public policies affect the growth of SME development and progress, with this study has in center the analysis of economic activity and their finances. I have been trying to gather materials, to develop a real analysis and research on the development of SME organizational structures, how they change and how they manage their financial resources, this financial analysis serves to study the strategy and organizational structure of a business.

"The Design and implementation of policies that impact dynamic growth and sustainable development of the industry sector and SME-S, in accordance with the national strategy for development and integration, respect for environmental protection and social development,in order to ensure a sustainable and long-term through the promotion of domestic and foreign 
investments, exports, the application of new technologies, institutional administraton strengthen, the specialization of the workforce, penetration into the open regional European markets and wider."

\subsection{What are public policies?}

In the Anglo-Saxon term, the term policy, looks opposite to the term politics, in the mere meaning of party and politicians' reports. In continental Europe, the idea is that politics in terms of politics and politics in the sense of politics are two aspects of the same phenomena.In the Anglo-Saxon approach the two terms recognize not only lexical difference but also an essential one. In Europe, only the UK recognizes the difference between politics and policy due to the uniformity of language and the traditional cultural exchange with the USA. (Dennis A, 2009)

For all other European countries, terms preserve their imported form, and the distinction between politics and politics is practically in the process. Even in Albanian, differences in terms are not apparent because they are included in the same word: "politics".

\subsection{What is good governance?}

Derivingfrom the New Public Management (Micro-economic theory and administrative science), the notion of "good governance" has spread in the 1990's by the World Bank as a necessary condition of development policies. For the World Bank, governance includes norms, traditions and institutions through which a country exercises its authority over the common good in the development optics. (Moulis S, 2011)

Governance, according to the IT Governance Institute, "aims to give strategic orientation, to ensure that objectives are achieved and that risks are properly managed and resources are used in most responsible way." It cares with priority to respect the interests of those "having rights" (citizens, public authorities, shareholders, etc.) and to make their voices heard in managing the affairs (ITGI 2012)

The Taylor rule for defining an optimal policy should be modified, taking into account the most direct way in determining exchange rates of monetary policy instruments. (Dumi A, Leadership, 2016) So, good governance is related to the functioning of public powers, in particular the state itself. "The way of exercising power" should respect these principles: Tested empirical did not supported this assumption and consequently it is supposed that this movement of the exchange rate is not fully reflected in price levels.Already there are many models / theories that explain why such disregard is incomplete.Tested math model and ESSP are supported this data of this paper research correctly.

\subsection{The aim of this study, data analyze}

The aim of this study is to provide empirical evidence on the extent of the contempt of the exchange rate with the rate of inflation in Albania. The study of this connection is motivated by the impact that has the exchange rate in an economy as small and open economy is Albanian. In Western societies regulated by liberal democracy, governance refers to interactions between the state, political bodies and society, including lobbying systems and coalitions of public and private actors. Good governance aims to make the most efficient and closest public action for the public good and the general interest as well as legitimate. It seeks to make the societies more manageable and more balanced, so that they do not over-exploit their resources and will be able to renew them. 


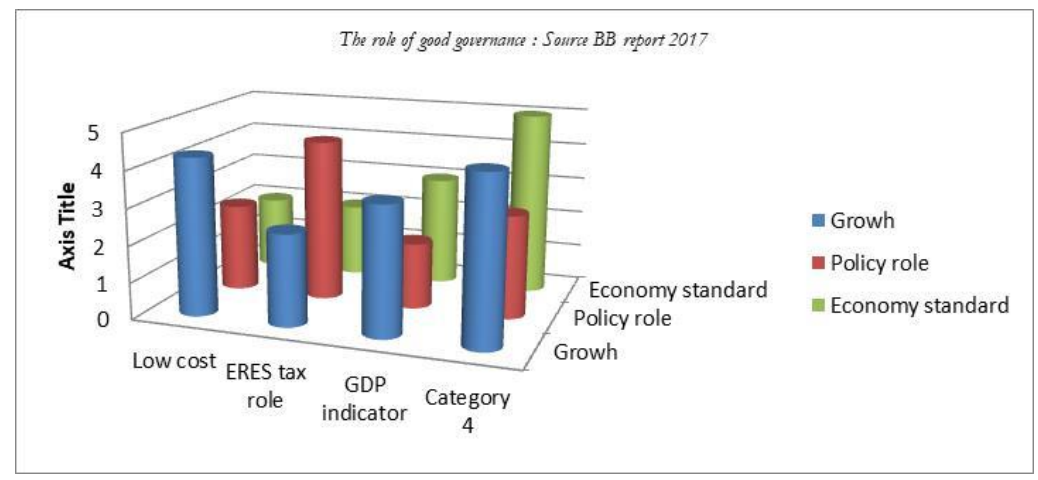

Given the importance of the exchange rate on the main elements of the economy, the Central Bank has not ignored the developments in the exchange rate in Lek, although the conditions were of floating exchange rates. (Ruli G, 2007)

The European Commission has recorded its notion of governance in the White Book of European Governance. Thus, the expression European Governance defines the rules, processes and behaviors that influence the exercise of powers at European level, especially in terms of openness, participation, accountability, efficiency and coherence. These five "principles of good governance" strengthen those of subsidiary and proportionality. This definition also is introduced in the Lisbon Treaty. (EGE Commission 2012)

\subsection{Historical Public Policy Changes}

The state has historically been built through the production of public policies: it has progressively enriched its fields of action by taking different views over the centuries. There are many stages that correspond to the specific functions of the State:

State action is a direct intervention, made through administrative instruments such as police, army, justice, and through the production of rules of law;

Responsibility is perceived as collective and not just individual, collective insurance systems are set for accidents at work;

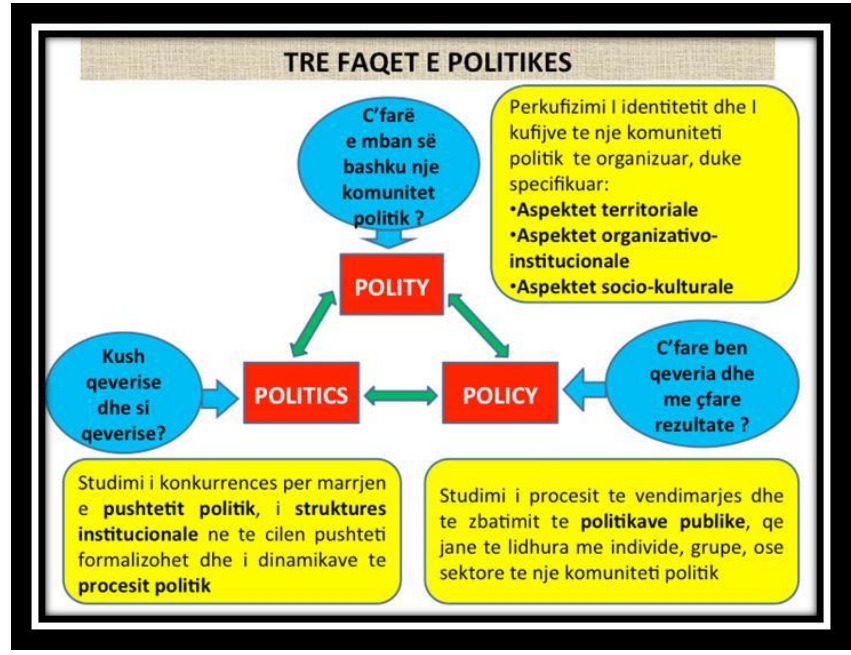

Source: State.com. Albania economy development, 2013 
- Accountability, which implies the responsibility of decision-makers, controls upon administration, control over public markets, public money management, and so on.

- Empowerment, which means giving all actors the opportunity to participate in the development process.Critics of "good governance" see it as an ideology ofsocial -state disengagement, even a theory of State decomposition, which has started to operate since the neoliberal turn of the 1980's.

H1: They denounce abandoning the term "government" and the use of the term "governance", explaining that it is about demolition of the state's decision-making power as a guarantee of popular sovereignty, replacing it with participatory of democracy, which has no real political attribute.

$\mathrm{H} 2$ : But how these policies can be used with inflation targeting?

\section{The Purpose of the Study}

These developments are closely monitored by the Central Bank and in certain moments it has intervened through monetary policy to avoid fluctuations regarded the distorting. This is done because the exchange rate is one of the main variables involved in the process of forecasting inflation.(Guxholli Z, 2009)

According to them, "government" in governance shows that it is passed from a civilization of popular sovereignty embedded in Republican constitutions, the guarantor of the general interest, in a pragmatic, utilitarian society, the guarantor of special economic interests, in which the notion of common good no longer has place.In this very intensive theoretical debate of recent years, many other "good governance" statements take into account the legitimacy and legality of good governance. It can be said that a situation is legitimate when it is accepted by those who are subject to its consequences.

.Albania strengthened access to credit by amending the Albanian Civil Code and the Law on Securing Charges, and by adopting a new Insolvency Law. It is now possible to grant a security interest over any type of movable property - including tangible and intangible assets - and secured creditors are given absolute priority within insolvency proceedings.

Labor Market Regulationin Albania

Albania amended legislation to reduce the maximum number of our, allowed in a workweek and to mandate that women and men be given equal remuneration for work of equal value.Source: DBA, 2017

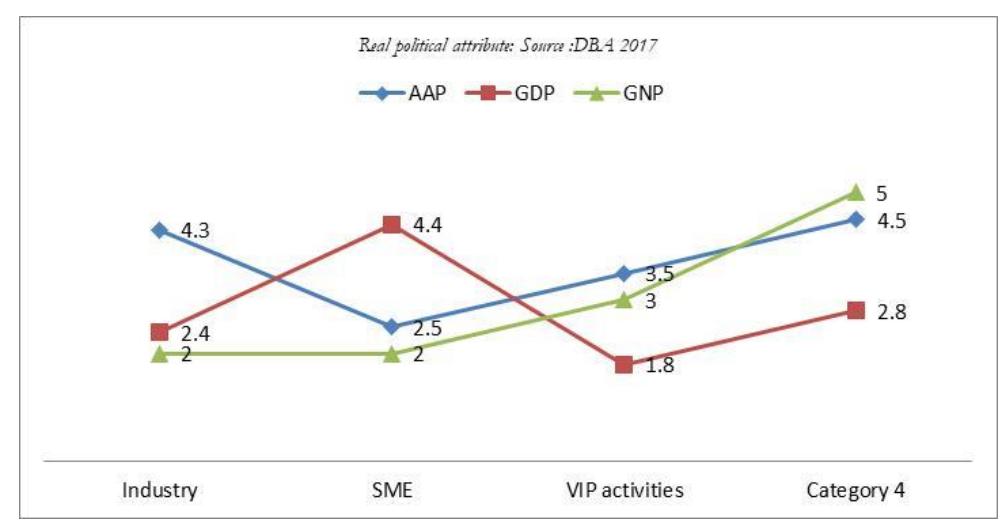

Dealing with Construction Permits: Albania made dealing with construction permits easier by reintroducing the issuance of building permits and streamlining the process of receiving the final inspection and compliance certificate. Source: DBA, 2017 


\section{Literature Review and Hypotheses}

To give an answer as best as possible to this issue will be based the empirical research, due to the different specific factors in economy of the country. In 2012Vlora university and Dumi Professor of economy in management department, has made a research in 13 different countries which have an economy in transition and in developing,this is for the hypothesis that the exchange rate belongs to monetary reaction function.

The indicators are used to analyze economic outcomes and identify what reforms have worked, where and why. This economy profile presents the Doing Business indicators for Albania. To allow useful comparison, it also provides data for other selected economies (comparator economies) for each indicator.

\section{Research Goal}

In the case of Albania maintaining macroeconomic interior balancing in terms of liberalization of the economy constitutes a major challenge for our economy has a huge deficit of current account and a high trade deficit

The strategy based on its goals will be oriented according to some specific key directions:

1. The capacity Increasement of local companies need to absorb new knowledge and experience in promoting investment. Improve and establish a network of international cooperation (internationalization) through professional networks between business partners, knowledge exchange, learning and management development, marketing and other business skills such as applying productivity-enhancing methods and preparing qualified employees, etc.

2. Offering products and services based on resource efficiency and clean production as a prerequisite that will lead to the restructuring of non-food industries, aiming at increasing competitiveness with target markets, diversifying export products. The measures and activities undertaken will create the basis for a real position of the country's industry towards the global market, towards the development of new products and services based on a sustainable infrastructure.

3. Innovative business development, based on the research and development of knowledge both from the public and private sectors. Encouragement and cooperation between science and industry, cooperation with universities and research centers, technological infrastructure development, creation of industrial parks and parks, increased application of new technologies and protection of industrial property rights.

4. SME development and Entrepreneurship will be achieved with the annual increase in the number of innovative enterprises through better funding. The one is by constantly improving the business climate, promoting entrepreneurial spirit, lifelong learning. This development process will be accompanied by the introduction of new financial instruments, for all SME-s, and in particular in support of businesses run by women or in their start-up phase.

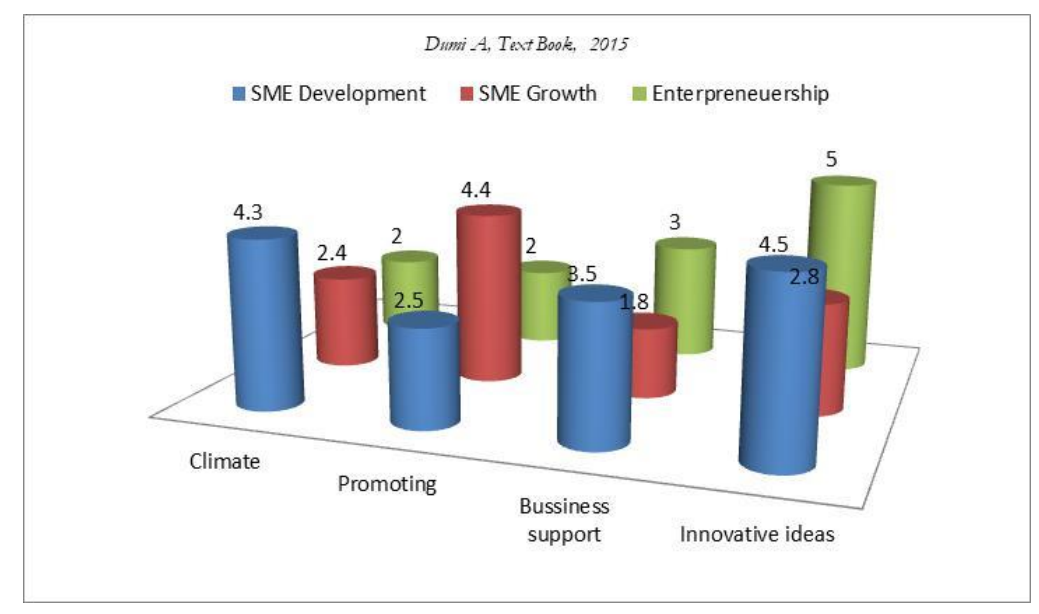


5. The Development of industrial clusters through clusters, through the co-operation of public and private institutions, focusing on innovation, marketing, management, technological incubator development, the participation in joint training across the chain of cluster-based actors, developing partnership activities throughout the entire product and service of delivery chain by cluster group.

\section{Problems related to the SME sector}

\subsection{The current development of the SME Sector}

According to the Global Competitiveness Report of the World Economic Forum 2013-2014, in the overall ranking, Albania is ranked 95th out of 148 countries / economies with a downturn in the 6-nation overall rankings from last year. Albania is classified in the group of countries that are in the second stage of competitiveness development (also called the "economic efficiency boost stage").

The last part contains the main conclusions drawn from the analysis of the connection that the exchange rate to inflation. Verification of hypotheses and questions that are raised for inflation connection with other elements of macro economic. The development of Albania's economy has gone through this major periods. (Ajis 2016)

a-1991-in this period the country's economy was dominated by a decrease in real GDP social and economic disruption. In this period, we have a higher inflation rate during this period.We have a decrease by two thirds of the level of income and inflation compared with 1989.(Calvo, G.A. 1999)

\section{Conclusions}

The exchange rate is very important for countries in developmentalso for developed countries too. In the longer term the exchange rate is affected by product of economy sectors between Albania and other countries, remittances and openings and trade agreements. Due to the different economic phenomenal that brings the economic crisis (inflation, rising prices) employees are more sensitive to the level of their salary and wage increases tend to seek or ask for a job that are paid more.(Dumi A, Leadership 2016)

Doing Business for Albania, sheds light on how easy or difficult it is for a local entrepreneur to open and run a small to medium-size business when complying with relevant regulations. It measures and tracks changes in regulations affecting eleven areas in the life cycle of a business: starting a business, dealing with construction permits, getting electricity, registering property, getting credit, protecting investors, paying taxes, trading across borders, enforcing contracts, resolving insolvency and employing workers.

1. The European Investment Fund ( $\mathrm{FEI}$ ) and ProCredit Group will provide an additional $450 \mathrm{~m}$-euro fund for innovative SME businesses, bringing a total of $820 \mathrm{~m}$ euros to these businesses

2. In June 2017, exports of goods amounted to ALL 23 billion, down $0.3 \%$, compared to the same period a year ago and by $7.1 \%$, as compared to the previous year.

3. The Albanian SME Institute SME Albania held today the closing ceremony of the first edition of the Summer Academy for SMEs, organized in cooperation with Köstinger Consulting. In this ceremony were present participants of the Summer Academy

4. Have good financial management and formulation of strategies that increase sales and profits. These will be the basics that are being followed for entrepreneurs with the launch of the Summer Academy for SMEs

5. $59 \%$ of Albanian youth are inclined towards entrepreneurship. However, very few know how to get started. "Shpk, Sha, access to credit: are unknown concepts for most of them

\section{References}

[1] Emmett, Boris, and Jeuck, John C. Catalogues and Counters; A History of Sears, Roebuck \& Co. Chicago: University of Chicago, 1950.

[2] Galbraith, John Kenneth. The New Industrial State. Boston: Houghton Miffliin, 1967. Landes, David Georg. Der Weg der Elektrotechnik; Geschichte des Hauses Siemens. Freiburg: Alber, 1961.

[3] Reader, W.J. Imperial Chemical Industries: A History, vol. 1, 1870-1926. Oxford University Press, 1970. 
[4] Nevins, Allan, and Hill, Frank E. Ford: Decline and Rebirth 1933-1962. New York: Scribner's, 1962/3.

[5] Schumpeter, Joseph. The Theory of Economic Development. Cambridge, Original Edition 2014

[6] S. The Unbound Prometheus; Technological Change and Industrial Development in Western Europe from 1750 to the Present. Cambridge University Press, 1969.

[7] Schumpeter, Joseph. Capitalism, Socialism and Democracy. New York: Harper Bros., 1942. Siemens,

[8] Zeninn Mass.: Harvard University Press, 1934; Original German Edition, 1911. 